\title{
La forma de los objetos
}

\author{
Roberto Flores' \\ https://orcid.org/0000-0003-3623-1495 \\ I - Instituto Nacional de Antropología e Historia \\ Cidade do México, México
}

Resumen: La identificación de los objetos a partir de su forma es una tarea que realizamos cotidianamente sin mayores dificultades y sin preguntarnos mayormente el modo en la identidad adviene a la forma. La semiótica asume la tarea de describir ese proceso desde el momento en que la identidad del objeto, su categorización, es concebida en términos de significación. Sin embargo, al abordar dicha empresa, surge inmediatamente la dificultad de describir mediante un método general la diversidad de formas a las que el hombre se enfrenta. Aquí se propone, realizar la descripción de formas tridimensionales a partir de imágenes bidimensionales y con ayuda de un análisis cualitativo en términos de puntos de referencia inscritos en una rejilla posicional. El artículo justifica la pertinencia semiótica del método adoptado e ilustra su aplicación mediante un estudio de recipientes mayas prehispánicos.

Palabras clave: forma; contorno; perfil; punto de referencia; rejilla posicional.

Abstract: The shape of objects - The identification of objects based on their form is a task that we carry out on a daily basis without much difficulties and without asking ourselves how the identity comes to the form. Semiotics assumes the task of describing this process from the moment in which the identity of the object, its categorization, is conceived in terms of meaning. However, a difficulty immediately arises of describing by a general method the diversity of forms that man faces. Here it is proposed to carry out the description of three-dimensional shapes from two-dimensional images and with the help of a qualitative analysis in terms of reference points, inscribed on a positional grid. The paper justifies the semiotic relevance of the adopted method and illustrates its application through a study of pre-Hispanic Mayan vessels.

Keywords: shape; contour; profile; landmark; positional grid.

Resumo: A forma dos objetos - A identificação dos objetos a partir de sua forma é uma tarefa que realizamos cotidianamente sem maiores dificuldades e sem nos perguntarmos de que modo a identidade surge da forma. A semiótica asume a tarefa de descrever esse proceso a partir do momento em que a identidade do objeto, sua caracterização, é concebida em termos de significação. Sem dúvida, ao abordar essa tarefa encontra-se imediatamente a dificuldade de descrever mediante um método geral a diversidade das formas que o homem enfrenta. Aquí é proposto fazer a descrição das formas tridimensionais a partir de imagens bidimensionais e com a ajuda de uma análise qualitativa em termos de pontos de referência inscritos na grade posicional. O artigo justifica a pertinência semiótica do método adotado e ilustra sua aplicação por meio de um estudo de recipientes maias prehispânicos.

Palavras-chave: forma; contorno; perfil; ponto de referencia; grade posicional. 


\section{Introducción}

La obra de arte torna la percepción larga y laboriosa, dice Viktor Shklovsky (1973, p. 96), formalista ruso en un texto recogido en su Teoría de la prosa, lo mismo es posible decir de la semiótica de los objetos. El presente trabajo aborda semióticamente la forma de los objetos: esto significa que busca arduamente el significado de los objetos, más precisamente el significado de la forma (shape) de los objetos, aquello que nos hace decir un vaso es un vaso. Lo hace mediante una descripción cualitativa y no cuantitativa, es decir, en términos de cualidades sensibles contrastantes; asimismo toma de distancia con respecto a su objeto, distancia que en fenomenología y en los formalistas rusos ha tomado los nombres respectivos de reducción y desfamiliarización. Define desde esta disciplina el concepto de forma, entendida como el contorno del objeto (a no confundir con la silueta que es una imagen del contorno obtenida desde un punto de vista específico) ${ }^{1}$, y justifica un procedimiento de reconocimiento de formas específico de la semiótica. El procedimiento consiste en el empleo de una rejilla posicional bidimensional que se aplica a las distintas facetas que presenta el objeto. Este recurso es justificado y comparado en sus alcances con un enfoque directamente tridimensional. También se opera un contraste con otros enfoques, que son los psicológicos y computacionales. La confrontación disciplinaria permite precisar la noción de forma con la que el estudio de la significación de los objetos trabaja y aclarar las elecciones conceptuales que es realizar, así como algunos riesgos que conlleva el procedimiento. Finalmente se presenta un ejemplo y se señalan las vías que se abren a la descripción y reconocimiento de formas 3D en semiótica de los objetos.

\section{Enfoques psicológico, computacional y semiótico}

Antes de presentar el procedimiento semiótico, es necesario señalar las razones de sus diferencias con procedimientos de reconocimiento de forma en psicología de la percepción y en escaneo de objetos tridimensionales.

\section{Forma 3D y contorno 2D}

En psicología de la percepción se considera (HELMHOLTZ, 2000, p. 533-534) que el reconocimiento de un objeto 3D se realiza por la composición de múltiples imágení; no se trata de obtener un percepto a partir de un estímulo visual, sino un objeto semiótico. El producto de la operación constructiva no es la magnitud de origen, el objeto del que se partió, sino su contorno, es decir, la forma del objeto, una magnitud semiótica obtenida por reducción.

Aunque inverso a las propuestas por la psicología de la percepción, debe señalarse que el procedimiento semiótico no es comparable con la percepción visual, puesto que no tiene un carácter psicológico, sino simplemente un valor modelizante y por ello

1 La palabra forma es polisémica y en semiótica ya tiene sus usos consagrados que difieren de la acepción aquí utilizada. Por esa razón es deseable utilizar el término contorno que, si bien presenta algunas dificultades en su utilización, es más preciso. En efecto, habitualmente se entiende por contorno de un polígono es su perímetro o el conjunto de líneas que delimitan un objeto o cuerpo, pero en este caso se refiere a la superficie que delimita su exterior. 
las imágenes con las que se trata están desvinculadas de su situación y se requiere de un recorrido completo alrededor de la pieza estudiada: es un recurso práctico para acceder a la magnitud 3D considerada directamente inaccesible y no de una hipótesis acerca de la conformación de una percepción y, mucho menos, de una consideración ontológica acerca de la naturaleza de los objetos tridimensionales.

La modelización semiótica también presenta analogías y diferencias con la reconstrucción computacional en 3D a partir de múltiples imágenes tomadas desde todos los ángulos: en ese caso la dirección de ambos procedimientos también es inversa (3D> 2D, en semiótica y 2D>3D, en el escaneo); la diferencia del escaneo con la visión, es que el procedimiento no es perceptual sino representacional y, por lo tanto, al igual que la modelización semiótica la imagen 3D resultante no es situada. Pero, si bien el procedimiento semiótico efectúa un recorrido alrededor del objeto, su meta es obtener una o varias imágenes 2D, susceptibles de ser analizadas, sin que sea necesario un análisis directo de la imagen 3D resultante: la tridimensionalidad es producto de una síntesis intelectual (no perceptual) de las imágenes y no de las imágenes directamente.

La forma del objeto se establece a partir del perfil, mejor dicho, de los perfiles que ofrecen imágenes de un mismo objeto desde distintas perspectivas. Esto plantea un problema para el reconocimiento de la tridimensionalidad que los psicólogos de la percepción han estudiado desde hace tiempo (HOCHBERG and McALISTER, 1953): al enfrentarse a una imagen 2D, es posible preguntarse cuándo y cómo es que esta imagen es susceptible de ser considerada como la imagen de un objeto 3D. Las respuestas se han apoyado en el grado de simplicidad o complejidad de la información contenida en la imagen, en la distinción entre figura y fondo, en la orientación y posición del objeto representado, en informaciones contextuales y en la familiaridad con el objeto representado. Las respuestas y los problemas que despiertan no atañen a la semiótica, pues se refieren a la manera en que la información ofrecida por una imagen retiniana permite reconstruir cognoscitivamente un objeto distal. En cambio, la descripción semiótica de la forma consiste en construirla a partir de la multiplicación de perfiles - le corresponderá al analista realizar la síntesis -, sin consideración ni del objeto ni de la imagen en sí misma, sino sólo en función del perfil que se ofrece a la vista, en una suerte de reducción o abstracción del objeto y de la imagen: tanto el objeto como la imagen pueden contener una cantidad enorme de información que no interesará, salvo aquella referente a los contornos. Esto significa que la tarea del análisis semiótico de la forma consiste en establecer correspondencias entre distintas magnitudes semióticas.

En el contorno 2D el ser humano asume que ve el contorno 3D del objeto en sí mismo y no la imagen: hacemos caso del perfil en tanto faceta del objeto y no de una imagen, cayendo - si se quiere ver así - en el efecto de realidad. Nótese que estamos frente a tres tipos de magnitudes distintas: el objeto, la imagen y la forma. Se trata de poner en relación tres magnitudes semióticas disímbolas, en un ir y venir entre el objeto y la imagen. Son tres objetos diferentes, aunque unilateralmente dependientes entre ellos: el perfil presupone el objeto y, a su vez, la forma sintética presupone los perfiles de los que se obtuvo. 
Al ser distintos debe tomarse en cuenta de que la asociación no es mecánica y está sujeta a desfases: un contorno 2D requiere de un acto interpretativo para ser asociado a un contorno 3D; esa interpretación presenta varios grados de complejidad en función del perfil presentado.

En suma, aunque la psicología, la computación y la semiótica recurren a inputs en 2D para obtener imágenes en 3D, los procedimientos no son los mismos pues tienen objetivos distintos: la percepción de un objeto, la reproducción y la modelización. Debe pues reconocerse las diferencias entre preguntarse cómo se percibe, cómo se visualiza y qué se percibe. De esta manera queda claro que la descripción semiótica de formas tridimensionales debe recurrir a procedimientos ad hoc, sin plegarse a otros proyectos disciplinarios.

\section{Definiciones}

Para justificar el enfoque elegido es preciso hacer algunas distinciones conceptuales y terminológicas. Ariza (comunicación oral) nos dice que la shape es la superficie del objeto y que responde a una geometría: aquí el término en inglés es traducido como contorno, que es una superficie cerrada que alterna planos y curvas tanto convexas como cóncavas. En términos aspectuales el contorno es una forma bidimensional perfectiva (cerrada), dotada de discreción, es decir de una frontera que establece una discontinuidad entre lo que debe ser considerado como lo mismo (el objeto) frente a lo otro (el entorno). Dada la dificultad para describir directamente en términos semióticos el contorno tridimensional de un objeto, se torna necesario recurrir a imágenes bidimensionales que captan las distintas facetas del objeto. Mediante este procedimiento el contorno se aborda como una colección, potencialmente infinita, de facetas. La descripción consiste entonces en reducir el conjunto infinito y abordar el contorno a partir de un inventario limitado de facetas para reconocer en ellas los puntos en que contrastan con el entorno del objeto: de esta manera, para cada faceta registrada en una imagen, se obtiene un perfil de la pieza estudiada. Ese perfil consiste en la línea que traza la frontera entre lo mismo y lo otro; es una línea cerrada que alterna rectas y curvas. De manera que la detección de la forma de un objeto pasa por su proyección en dos dimensiones (figura 1).

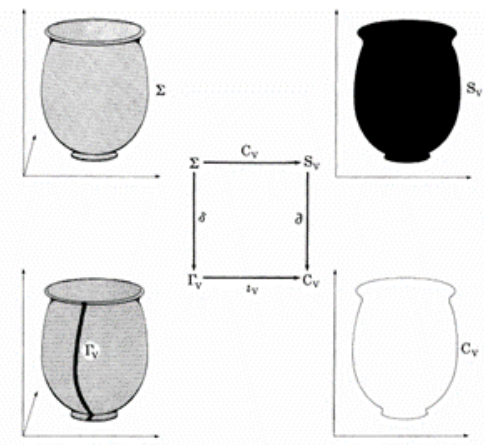

Fig. 1. Tomado de Marr, 77. En nuestra terminología -que no es la de Marr- y siguiendo las manecillas del reloj, empezando por el extremo superior izquierdo: contorno del objeto 3D, presentado desde una de sus facetas, el contorno $2 \mathrm{D}$, el perfil y línea de perfil en el objeto 3D (la línea negra). 
Un punto que es necesario aclarar consiste en el hecho de que, el contorno 2D de un objeto «no depende de la naturaleza de los elementos que lo producen» (PIZLO, 2008, p. 28). La tarea de identificar la naturaleza de esos elementos corresponde a la mereología y a la morfología, ya sea que se trate de un objeto unitario, ya sea que sea una ilusión producida por la alineación de objetos heteróclitos. El contorno es, pues, indiferente a la materialidad del objeto: el único rasgo que interviene es la superficie que marca la frontera entre el objeto y su entorno. Al respecto es posible considerar el caso de las sombras chinas que producen un contorno ilusorio, pues sugieren un objeto susceptible de ser identificado, pero que está formado por elementos ajenos a la forma sugerida (figura 2): en esos casos las formas existen y son reconocidas, sin que sea preciso un objeto material coincidente. Por estas razones es preciso considerar que el contorno es una magnitud semiótica construida por el análisis que se sitúa entre la percepción del objeto sensible y la intelección de la forma.

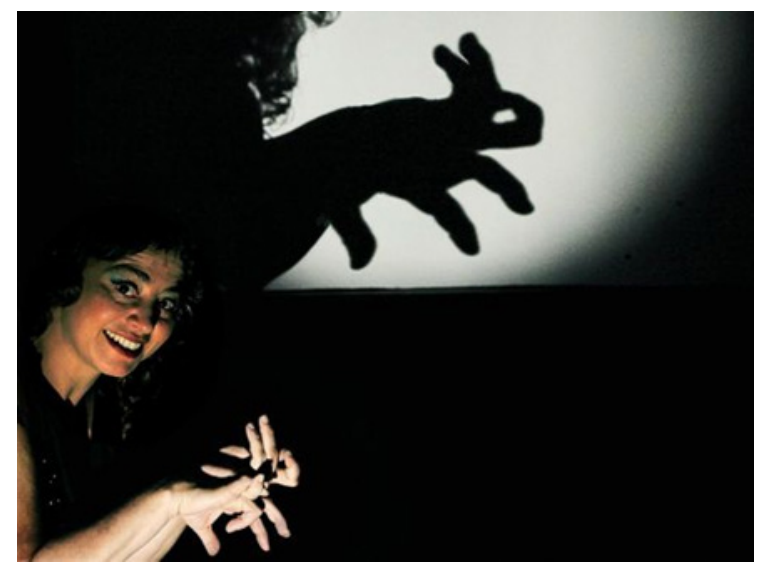

Fig. 2. Sombras chinas. <https://http://www.redteatrosnavarra.com/es/users/sombras-chinas-valeria-guglietti>.

La imagen (figura 3 a) presenta la figura de un loro cuyo contorno se muestra desde una de sus facetas, ese contorno es mostrado en (b) en gris claro y la línea negra circundante (en b) corresponde al perfil de la faceta elegida.

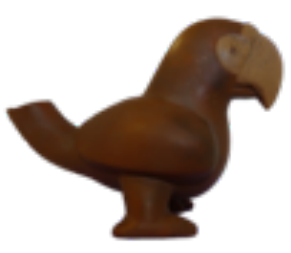

a)

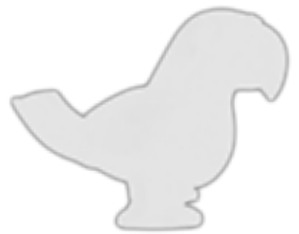

b)

Fig. 3. Contorno, faceta y perfil. Cerámica prehispánica del Occidente de México. 
La selección de facetas plantea problemas que es preciso indicar. En el caso de los cuerpos de revolución basta la alternancia de rectas y curvas del perfil para ofrecer información sobre el volumen. Cuando la forma es perfectamente regular y circular, basta con un plano para detectar la forma, pero cuando la forma es poliédrica o irregular, se requiere multiplicar los planos que permitan detectar las diversas facetas que ofrece un objeto. Esto plantea un problema, pues no hay un límite a priori en el número de facetas que ofrecen los objetos. Una irregularidad o el vértice de un poliedro ofrecen la posibilidad de múltiples puntos de vista desde ángulos distintos que van variando gradualmente:

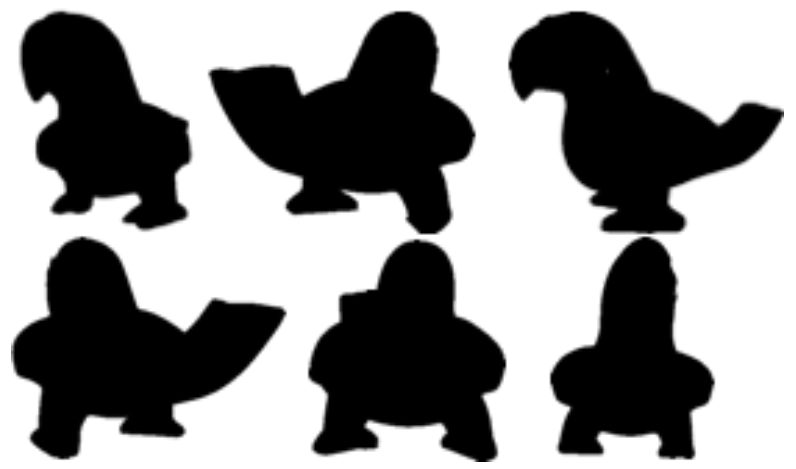

Fig. 4. Diferentes facetas.

De ahí que, si se quiere dar cuenta de esa gradualidad, se tendría que multiplicar el número de planos al infinito. En consecuencia, se torna necesario limitar el número de vistas: esto significa que el analista debe contar con un criterio de relevancia que aplicará a la pieza estudiada.

La psicología de la percepción ha abordado este problema desde el concepto de constancia de la forma (PIZLO, 2008, p. 1). Brevemente dicho, es posible definir este concepto como el hecho de que una forma sigue siendo reconocible a pesar de las variaciones en las condiciones en que se presenta el estímulo, como son posición, iluminación, tamaño, color, etc. Evidentemente, el semiotista posee una competencia perceptiva que le permite identificar el objeto a pesar de las diferencias en el modo en que se presenta. Pero esta competencia no basta para el análisis, pues se requiere un método para vincular explícitamente los distintos perfiles y contornos de modo que se ofrezca una descripción sintética y unitaria de ellos. Esto supone elegir un número limitado de vistas que serán consideradas y que, de acuerdo a principio relacional de la semiótica, serán traducidas en elementos contrastantes.

Hay tres criterios que es posible considerar para efectuar la selección. El primero descansa en la corporalidad, es decir, en la consideración de que las construcciones mentales 
se realizan de acuerdo a patrones impuestos por la concepción que los humanos tienen acerca de su propio cuerpo: esta proyección corporal imaginativa (LAKOFF y JOHNSON, 1999, p. 37) es responsable de la asignación de ejes y puntos de vista que calcan la bilateralidad y la frontalidad del cuerpo humano. De esta manera es posible considerar puntos de vista privilegiados como son frontalidad, la lateralidad, la posterioridad, el cenit y el nadir. El segundo descansa en la extensión de las áreas de exposición, que van de una máxima a una mínima y pasan por grados intermedios: la dificultad de este criterio es que, si bien los grados máximos y mínimos son limitados en número, los puntos de vista de áreas intermedias abren un abanico extremadamente grande de opciones. La tercera opción se emparenta con la primera en que se apoya en una orientación corporal, pero dictada en este caso por las posiciones más estables que ofrece el propio objeto: la limitación en este caso responde a que en muchos casos ofrece varias opciones que se encuentran en igualdad de circunstancias, por lo que el criterio es insuficiente.

Los criterios disponibles conducen a privilegiar ciertas facetas del objeto, que adquieren entonces el estatuto de portadoras, aunque sea parcialmente, de la información requerida para identificar y categorizar el objeto descrito. Cualquiera que sea el criterio retenido, las facetas permiten el reconocimiento del objeto al ofrecer una imagen prototípica del mismo, esa imagen es susceptible de encontrarse anclada en la cultura bajo la forma de un estereotipo. Prototipo y estereotipo coadyuvan así a la captación de la forma, pero lo hacen desde ángulos distintos: uno desde la cognición y el otro desde la cultura.

Como se aprecia, la selección de facetas es un problema abierto en semiótica que requiere ser explorado y cuyas respuestas deben ser formuladas de acuerdo a principios fenomenológicos y estructurales para no ofrecerse simplemente como una lista de criterios.

Una vez seleccionada una faceta y trazado su perfil, que corresponde a una línea cerrada que enmarca un área y que se compone de rectas y curvas con distinta dirección (figura 5 a y b), es preciso marcar sobre él los puntos máximos que señalan los extremos del objeto (marcas en verde). Luego se indican los puntos de inflexión en donde la línea cambia de dirección (puntos azules). Cabe señalar que, como el perfil no señala la profundidad es necesario considerar esta información: algunas partes del perfil deberán ser ignoradas por encontrarse en un segundo plano (la punta inferior de la pata izquierda del loro) y otras deberán ser restituida al estar situada sobre un elemento de segundo plano (el arranque de la pata derecha que no se encuentra indicada por encontrarse al interior del área). Los puntos así obtenidos aparecen ahora como una constelación que permite restituir la información relevante del perfil y efectuar comparaciones con figuras similares. 


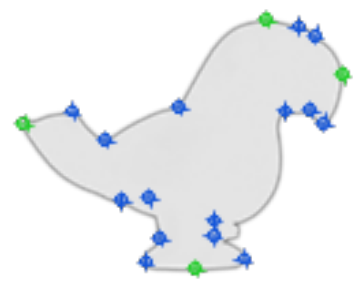

a)

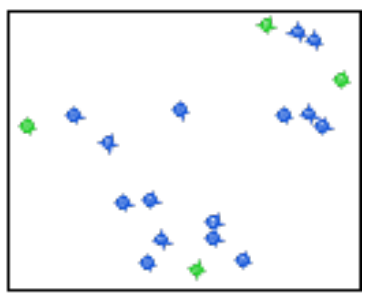

b)

Fig. 5. Máximas y puntos de inflexión

Pero antes de aprovechar esa información es preciso plasmar los puntos dentro de una rejilla posicional, para contar con un sistema de coordenadas.

\section{Rejilla posicional}

Una rejilla posicional es un recurso práctico utilizado en semiótica como parte de la operación de segmentación (GREIMAS y COURTÉS, 1982, p.347). Con respecto a la definición de procedimiento de segmentación cabe señalar que la identificación de contornos en objetos tridimensionales difiere del reconocimiento de sintagmas de textos en lengua natural. En un caso se trata de establecer las fronteras externas del objeto, sin consideración de las partes que compondrán el todo, mientras que, en el otro, se trata de reconocer unidades inmediatamente significativas.

En semiótica de la imagen se utiliza una rejilla posicional para establecer un sistema de localización al interior de la imagen, que permita ubicar los distintos elementos plásticos y figurativos que la componen y facilitar la detección de contrastes significativos. Una primera propuesta podría ser utilizar una malla esférica como sistema de coordenadas para determinar la forma del objeto mediante el establecimiento de una relación isomorfa (figura 6).
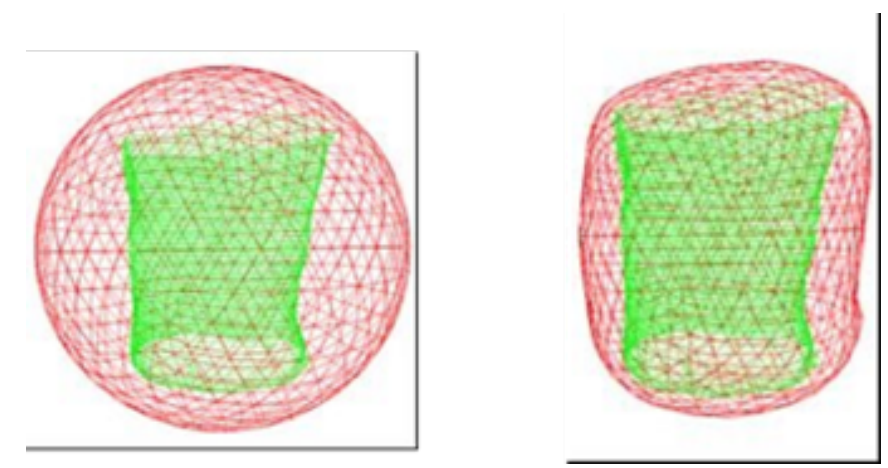

Fig. 6. Modelización de un objeto con ayuda de una malla deformable. Trujillo-Romero 2008, p. 53. 
En ese caso la malla se ve sometida a deformaciones que corresponden al contorno del objeto: la forma del objeto va a corresponder a la deformación de la malla inicialmente esférica que lo envuelve y la descripción del objeto será obtenida mediante la descripción geométrica de las diferencias entre ambas mallas. El procedimiento se aplica a objetos no situados - es decir, se aplica a objetos indiferentemente del contexto en que se encuentren -; es directamente tridimensional, por lo que evita el paso por la bidimensionalidad y ofrece un sistema de coordenadas correspondiente a la ubicación, dimensiones y angularidad de los poliedros que componen la malla. Sin embargo, su utilización en semiótica se ve limitada por el hecho de que se aleja de las formas naturales de la percepción, por lo que sus resultados no son traducibles en términos de una descripción comprensible por un lego, pues se presenta como un lenguaje técnico, lejano del lenguaje cotidiano. De hecho, esto ocurre con todo recurso a la geometría formal: una descripción geométrica es la imposición de un modo de lectura formal, pero no significa que la concepción del objeto o su recepción por parte de los observadores o usuarios lo sea, aunque es para todos obvio que existen muchos casos en que el diseño geométrico rige la producción del objeto. Si bien una rejilla esférica deformable permite situar el objeto con respecto a un sistema de coordenadas exterior a él, en cambio no permite detectar la forma (shape) del objeto que equivale a su contorno. En efecto, el contorno es el punto en que la forma del objeto contrasta con aquello que no es el objeto: el fondo. Al utilizar una malla esférica se pierde ese fondo y nos quedamos únicamente con el objeto: ya no hay contraste y, por lo tanto, no hay contorno

Por lo anterior es necesario proponer otro tipo de rejilla posicional que permita el análisis contrastivo del contorno. La formulación primera y más básica de la rejilla (THÜRLEMANN, 1982) consiste en dividir la imagen en distintas zonas al inscribir la imagen en un paralelogramo y trazar sus líneas medianas y diagonales. De esta manera se obtienen zonas en donde se sitúan los distintos elementos que componen el todo y que pueden ser localizados mediante un sistema de coordenadas (figura 7). El procedimiento propuesto consiste en descomponer un objeto tridimensional en un conjunto de facetas susceptibles de ser captadas como imágenes bidimensionales: el contorno perimetral de esas facetas corresponde a sus perfiles. Con ello la rejilla pasa a depender de los puntos de vista adoptados y de los criterios que presiden la elección de múltiples puntos de vista y la multiplicación rejillas bidimensionales: el procedimiento, aunque engorroso en algunos casos, es viable. 


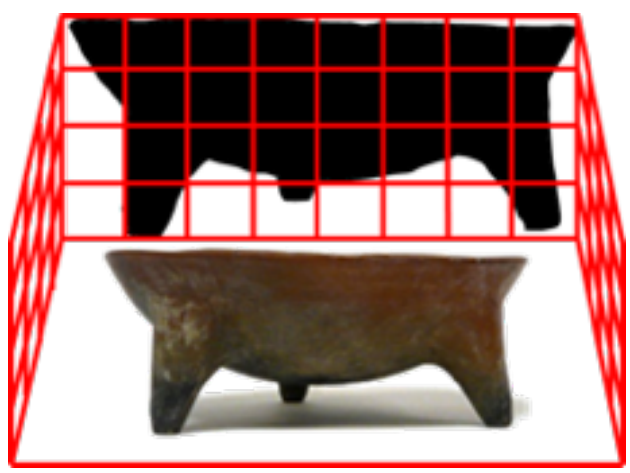

Fig. 7. Figura Vasija del occidente de México http://www.museoarocena.com/2015-04-15-05-24-08/ofrendas-de-vida>

Pero también es posible detectar puntos relevantes de la imagen cuya alineación es puesta en relieve por la rejilla. De esta manera, en el ejemplo del loro (figura 8), es posible situar las máximas y los puntos de inflexión dentro de la rejilla, lo que ofrece un sistema de coordenadas para localizar cada punto y permite, en el caso de figuras cercanas, comparar la posición de puntos similares.

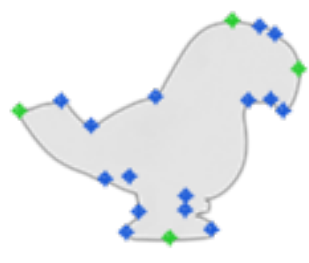

a)

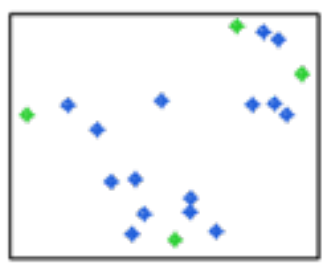

b)

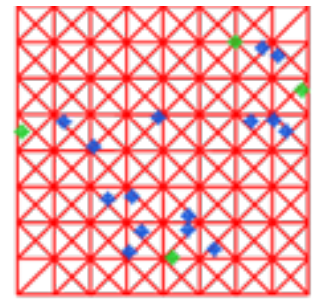

c)

Fig. 8. Máximas y puntos de inflexión en la rejilla posicional.

Al preguntarse sobre el "estatuto de realidad" de la rejilla inicial, Geninasca (2003, p. 63) la reelaboró al proponer concebir ese paralelogramo como el producto de dos cuadrados intersectados y multiplicó el número de líneas al dotar a cada cuadrado de sus propias medianas y diagonales. Este autor reconoce que procedimiento inicial propuesto por Thürlemann es evidentemente útil en el caso de imágenes pertenecientes a la cultura occidental en donde el formato cuadrangular ha sido especialmente favorecido, pero resulta problemático para otros formatos. Su reflexión lo conduce a proponer que la forma cuadrangular no responde a la naturaleza de soportes pictóricos específicos, sino que constituye "una estructura mental invariante" basada en las "direcciones fundamentales del espacio para el sujeto". De esta manera se ve llevado a privilegiar al cuadrado por encima del rectángulo. Más aún, al tomar en cuenta la existencia de campos locales que se inscriben dentro del cuadrado englobante: esos campos también adoptan formas 
cuadrangulares ordenadas simétricamente, al interior de las cuales también se trazan medianas y diagonales, como aparece en el ejemplo siguiente (figura 9). De esta manera la rejilla posicional ha servido como primer paso para identificar relaciones que forman parte de la estructura articuladora de la imagen: los puntos, líneas y planos que son identificados con ella forman parte de la configuración relacional que le otorga sentido a la imagen.

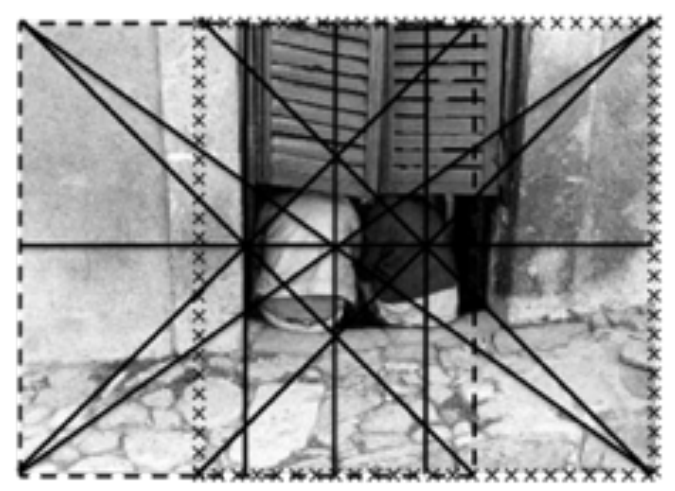

Fig. 9. Rejilla posicional de Geninasca: en punteado y con cruces los dos cuadrados. Jo Brenzo, Men in door. Ejemplo de R. F.

El privilegio otorgado al cuadrado en la rejilla de Geninasca no obedece a la preeminencia geométrica de esa figura, sino a principios fenomenológicos que rigen la percepción humana y que distinguen cuatro orientaciones en el plano: arriba/abajo, derecha/izquierda. La rejilla se sitúa entre el espacio de la imagen y el espacio en donde el observador se sitúa y desde donde adopta un punto de vista. El cuadrado no es una propiedad de la propia imagen, que quizá tenga algún otro formato, sino el producto de la actividad perceptiva del sujeto, que dirige su mirada desde el centro de su atención hacia las cuatro direcciones que su corporalidad privilegia: arriba, abajo, derecha e izquierda. La mirada emprende, pues, un recorrido desde el centro hacia los cuatro rumbos y abarca una extensión o campo de presencia, que adopta la forma cuadrangular: los costados de ese campo están constituidos por los límites del campo de presencia.

En semiótica visual la operación de segmentación se apoya en la relación entre el formato de la imagen y los formantes plásticos y figurativos que la constituyen: si bien los formantes pertenecen de propio al contenido de la imagen, el formato no, pues pertenece al soporte de la imagen. En el caso de la semiótica de los objetos el objeto es su propio soporte: no existe ningún elemento material que le dé formato, salvo su propia forma. Esta peculiaridad tiene grandes repercusiones al momento de establecer un protocolo analítico del objeto, pues resulta tentador aplicar una rejilla posicional para identificar tanto elementos significativos como la forma misma del objeto. Sin embargo, dada 
la ausencia de un soporte ajeno al objeto no es posible adoptar sin más las rejillas posicionales propuestas por Thürlemann y Geninasca.

Es posible, en cambio, adoptar una rejilla apropiada a los objetos: de esta manera se podría dar cuenta, en el caso de los recipientes cerámicos que sirven de anclaje para la presente reflexión, de la forma singular del recipiente mismo o de la distribución de sus elementos decorativos y de sus adpósitos (asas, vertederas, mangos, base, patas, etc.). Con este procedimiento también es posible tener un sistema de localización que sirva de marco de referencia común para efectuar comparaciones entre distintos recipientes y poder establecer una clasificación de recipientes y una eventual tipologización que permita la ubicación espaciotemporal de los objetos estudiados. De manera que la semiótica de los objetos tiene interés en utilizar una rejilla posicional adecuada a magnitudes semióticas tridimensionales. En el siguiente apartado se muestra la manera en que es posible utilizar la rejilla posicional de Thürlemann para la descripción comparativa de objetos regulares y la de Geninasca para la descripción singular de objetos irregulares.

\section{Análisis de caso}

Aunque las metodologías y las técnicas exigen rigor conceptual en su elaboración, éstas sólo se validan en el momento de su aplicación al estudio de casos específicos. Son dos los tipos de análisis que es preciso considerar: por una parte, la comparación de piezas de forma similar; por la otra, la descripción de piezas únicas que busca dar cuenta de su singularidad. En arqueología ambos tipos de análisis coexisten, pero sin que se preste mucha atención a sus peculiaridades respectivas. En muchos casos, el análisis comparativo es emprendida sin consideración de los rasgos singulares y, en el estudio individual de piezas es dejado al análisis iconográfico y a la historia del arte. A pesar de estas dificultades es posible proponer dos vías de descripción sobre la base del aparato conceptual común que aquí ha sido propuesto: un análisis comparativo y uno de piezas singulares. Por razones de espacio, sólo se presentará el primero.

La semiótica ha prestado poca atención a los análisis comparativos, pues la mayoría de los investigadores han dedicado su atención al estudio de piezas únicas que son histórica o estéticamente relevantes. Un punto relevante para entender los alcances y limitaciones de la presente propuesta es que se trata de una descripción de la forma de los objetos a partir de su contorno y no de una descripción mereológica o morfológica de los objetos (aunque estos otros enfoques también deben ser desarrollados). Con esta precisión es necesario explicitar los parámetros de la comparación: el contraste propuesto se realiza en perfiles sobre la base de las facetas elegidas. En ese sentido quedan fuera de consideración los elementos situados al interior de la curva que constituye un perfil y las consideraciones relativas al tamaño de las piezas, pues únicamente interesan las proporciones (no hay una métrica universal). 
Para objetos regulares y comparables es necesario utilizar la rejilla posicional 1 que consiste en un cuadrado dividido por una trama de líneas equidistantes verticales, horizontales y oblicuas y centradas alrededor de las medianas (figura 8). Para construir la rejilla se divide el cuadrado inicial en medianas y diagonales y se realizan subdivisiones de los cuadrados resultantes: este procedimiento se prosigue hasta obtener el grado de resolución deseado. Es necesario tomar en consideración que una trama laxa no permite identificar el perfil de la pieza, mientras que una trama muy cerrada se torna redundante y difícil de manejar cuando se enfrentan gran cantidad de datos.

Al utilizar la rejilla, cada faceta 2D se ajusta al tamaño de la rejilla para que coincidan en altura (aunque también sería posible hacer el ajuste a lo ancho: por ejemplo, en el caso de formas horizontales alargadas, como un plato o una escudilla), manteniendo las proporciones con la anchura: esto es con el fin de tomar en consideración únicamente las proporciones y no la métrica; de esta manera todas las piezas comparadas, sin importar sus dimensiones, serán inscritas en la misma rejilla². Cuando la anchura del contorno excede, aunque se mínimamente, es posible incrementar la anchura de la rejilla, al añadir columnas, pero respetando las proporciones.

Una vez inscritas las piezas en la rejilla se marcan aquellos puntos en donde el borde del contorno coincide con alguna línea de la rejilla (figura 10). Esto permite identificar el perfil de la pieza mediante puntos de referencia regularmente espaciados en la rejilla (semi-landmarks): estos puntos difieren de los indicados en el ejemplo del loro, pues no están determinados por las inflexiones en la curva que constituye el perfil, lo que en los análisis comparativos correspondería a elementos homólogos ${ }^{3}$. Al eliminar la rejilla, se obtiene una representación discreta del perfil del objeto (figura 10).
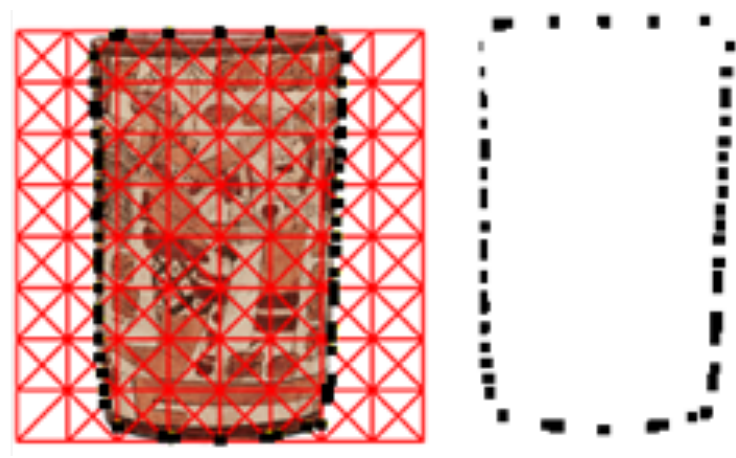

Fig. 10. Rejilla, contorno y perfil.

2 El procedimiento es similar al Análisis Procusteano Generalizado, utilizado en Morfometría (STRAUSS 2010, p. 87), en la medida en que se basa en el reconocimiento de puntos de referencia (landmarks y semi-landmarks) y exige que se realicen los procedimientos de rotación, sobreposición y ajuste de escala. Difiere de éste en que no se trata de un análisis estadístico, sino cualitativo, cuyo objetivo es determinar diferencias y reconocer contrastes en las variaciones de los perfiles.

3 En biología comparativa, la homología es la relación entre dos elementos de sendos organismos que tienen un origen evolutivo. Es posible trasladar este concepto a la comparación de artefactos. 
Al realizar el mismo procedimiento con todos los objetos que conforman el corpus, es posible sobreponer los perfiles obtenidos para compararlos. En el ejemplo que sirve de ilustración, se compararon 15 vasos provenientes de distintos lugares de la zona maya y de distintas épocas. La sobreposición permite identificar tanto las coincidencias, como la divergencia entre formas (figura 11). Dado que se ha considerado que estos objetos cumplían una misma función -beber chocolate-, resulta notorio la presencia de zonas de máxima coincidencia, en donde se sobreponen la mayor cantidad de perfiles, al lado de casos prácticamente únicos ${ }^{4}$. Pero de mayor relevancia es el hecho de que la distribución de perfiles no es homogénea, pues se aprecian hiatos de diversa envergadura (flechas negras horizontales en la figura 11 a). Si la variación en proporciones de los objetos fuera aleatoria, quizá debido a elecciones meramente estilísticas, debería observarse una distribución uniforme en la anchura, pero dado que esto no es así, es necesario considerar que los vacíos son significativos.

El análisis comparativo de las formas muestra que los vasos se distribuyen, grosso modo, en cuatro rangos de anchura, siendo el rango central el que posee un mayor número de ejemplares. Esto sugiere que se trata de, al menos, cuatro formas distintas, que quizá corresponda a sendos tipos de objetos, ya sea que la diferencia sea atribuida a un origen espacial o temporal distinto o a una diferencia de función. Al respecto, es de lamentar que la mayoría de los ejemplares descritos carecen de información contextual o dicha información es demasiado vaga para poder utilizarlos como punto de partida para inferencias tipológicas. A pesar de esta carencia, es de señalar que la ausencia de restos de chocolate indica que no existe unidad tipológica en la muestra comparada, así como tampoco en la que Loughmiller-Cardinal analiza. La autora señala que, de hecho, algunos de los vasos son ergonómicamente inaptos para ser sostenidos con la mano y que, otros, no tienen la impermeabilidad para retener líquidos, por lo que es probable que su contenido (si lo hubiera habido) era seco (quizá semillas de cacao o granos de maíz, p. 13). El hecho de que todos esos vasos estén profusamente decorados con imágenes similares a las halladas en los códices y de contenido mítico-religioso aboga por un uso ritual y por un valor suntuario. Lo anterior no significa que, en algunos casos, haya habido vasos de chocolate, pero esto no era la norma. La autora finaliza abogando por una mayor precisión en los criterios de clasificación, como la comparación aquí emprendida en torno a la forma.

4 Esta suposición ha sido refutada recientemente (LOUGHMILLER-CARDINAL, 2018) a partir de un análisis de sedimentos de 70 ejemplares que no arrojó evidencia de teobromina (compuesto presente en el chocolate), ni de microfósiles de cacao. 


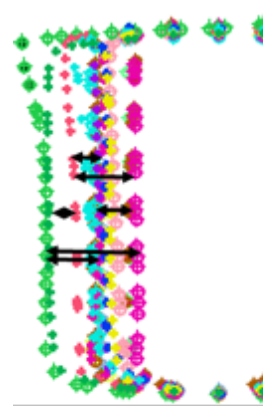

a)

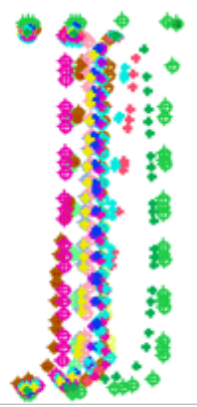

Fig. 11. Comparación de perfiles

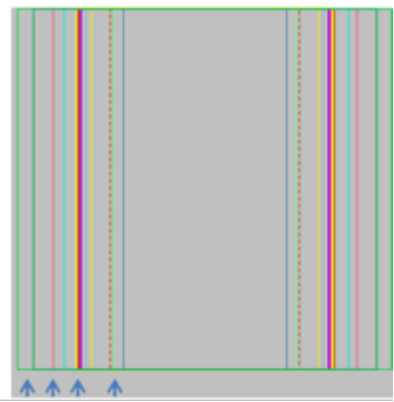

b)

\section{Conclusión}

Ciertamente el camino de la semiótica del objeto es arduo. La captación de un contorno no es directa, lo que significa que es preciso contar con una magnitud semiótica intermedia que sirva de traductor. Esa magnitud el fruto de una estrategia cognoscitiva de construcción de un objeto. Los contornos bidimensionales obtenidos a partir de los perfiles que ofrece la pieza estudiada tienen pues el estatuto de un artificio elaborado para permitir la descripción. El metalenguaje con el que se describe el objeto se aplica en primer lugar a esas imágenes y se traslada en un segundo momento a la forma 3D mediante un procedimiento de síntesis.

Los recursos empleados, las rejillas posicionales, varían tanto en función de la naturaleza del objeto descrito (regular o irregular) como del tipo de análisis (singular o comparativo). Pudiera objetarse que, con las dos rejillas, se pierde la unidad del análisis, pero esto sería ignorar que las rejillas son es más que un desarrollo de la rejilla básica de Thürlemann, sobre la que Geninasca elabora su propia propuesta. No hay, pues, ruptura.

Debe señalarse que con la detección de contornos no se agota el análisis de la forma, pues falta un acercamiento mereológico a las distintas partes que conforman el todo y un acercamiento morfológico que caracterice las distintas partes. Esos acercamientos recurren a formas geométricas básicas (pero sin caer en la geometrización a ultranza de la forma) y al reconocimiento de ejes de simetría. La presentación de estos otros dos acercamientos corresponderá a trabajos futuros.

Roberto Flores es pesquisador de Instituto Nacional de Antropología e Historia (Cidade do México).

rflores57@yahoo.com 


\section{Referencias}

FLOCH, J. M. Composition IV de Kandinsky, en HÉNAULT, A. Questions de sémiotique, pp. 123154, París, PUF, 2002.

FONTANILLE, J. Soma y sema: figuras semióticas del cuerpo. Lima, Universidad de Lima, (2017 [2004]).

HELMOHOLTZ, H. V. Treatise on physiological optics, vol. III. Bristol, Thoemmes, (2000 [1924]).

GENINASCA, J. El logos del formato. Tópicos del seminario 9. Puebla, BUAP, 2003.

GREIMAS, A. J.; COURTÉS, J. Semiótica: diccionario razonado de la teoría del lenguaje. Madrid, Gredos, (1982 [1979]).

LAKOFF, G; JOHNSON, M. Philosophy in the flesh. Nueva York, Basic Books, 1999.

LOUGHMILLER-CARDINAL, J. Distinguishing the Uses, Functions, and Purposes of Classic Maya "Chocolate" Containers: Not all Cups are for Drinking. Ancient Mesoamerica, pp. 1-18, Cambridge University Press, 2018.

MARR, D. Analysis of Occluding Contour. Proceedings of the Royal Society of London, Series B, pp. 441-467, Londres, Royal Society, 1977.

PIZLO, Z. 3D Shape. Cambridge, MIT Press, 2008.

PREUCEL, R. W. Archaeological Semiotics. New Jersey, Blackwell, 2006.

$\mathrm{ROSCH}, \mathrm{E}$. H. On the Internal Structure of Perceptual and Semantic Categories. Cognitive Development and Acquisition of Language, pp. 111-144, Academic Press, 1973.

SKLOVSKI, V. El arte como procedimiento, en AA. VV. Formalismo y vanguardia, pp. 87-113, Madrid, Alberto Editor/Corazón, (1973 [1929]).

STANGOR, C; SCHALLER, M. Stereotypes as Individual and Collective Representations, en MACRAE, N. C.; STANGOR, C.; HEWSTONE, M. Stereotypes and Stereotyping, pp. 3-37, Londres/Nueva York, The Guilford Press, 1996.

STRAUSS, R. E. Discriminating Groups of Organisms, en ELEWA, A. M.T. (ed.). Morphometrics for Nonmorphometricians, pp. 72-91, Springer, 2010.

THÜRLEMANN, F. Analyse sémiotique de trois peintures. Lausana, L'Âge de l'Homme, 1982.

TRUJILLO-ROMERO, F. J. Modélisation et reconnaissance active d'objets 3D de forme libre par vision en robotique. Institut National Polytechnique de Toulouse, 2008. En línea: <https://tel.archivesouvertes.fr/tel-00842693/document>. Consultado el 4 de enero de 2019.

Artigo recebido em 10/03/2020

e aprovado em 30/04/2020. 